\title{
Residual Stress Distribution of Asymmetric Quenching in Al-Zn-Mg-Cu Aluminum Alloy Plate
}

\author{
Yanan Li1 ${ }^{1,2,3 *}$, Guohui Shi ${ }^{1,2}$ \\ ${ }^{1}$ State Key Laboratory of Nonferrous Metals and Processes, GRINM Group Co., LTD., Beijing, China \\ ${ }^{2}$ GRIMAT Engineering Institute Co., LTD., Beijing, China \\ ${ }^{3}$ General Research Institute for Nonferrous Metals, Beijing, China \\ Email: *liyanan@grinm.com, shiguohui@grinm.com
}

How to cite this paper: Li, Y.N. and Shi, G.H. (2021) Residual Stress Distribution of Asymmetric Quenching in $\mathrm{Al}-\mathrm{Zn}-\mathrm{Mg}-\mathrm{Cu}$ Aluminum Alloy Plate. Journal of Materials Science and Chemical Engineering, 9, 11-18.

https://doi.org/10.4236/msce.2021.94002

Received: February 12, 2021

Accepted: April 2, 2021

Published: April 9, 2021

\begin{abstract}
The residual stress distribution for two strategies of asymmetric quenching in $\mathrm{Al}-\mathrm{Zn}-\mathrm{Mg}-\mathrm{Cu}$ aluminum alloy plates has been simulated using the finite element method. The results show that for asymmetric quenching between the upper and lower surfaces, the through-thickness asymmetric quenching residual stress distribution lies between the two distributions corresponding to the heat transfer coefficients on the upper and lower surfaces respectively. The surface and central stress magnitudes are equal to the average of the stress magnitudes corresponding to the two heat transfer coefficients. For asymmetric quenching of a single surface, the surface stress distribution is the same as the heat transfer coefficient distribution and the stress magnitude is equal to the stress magnitude corresponding to the average value of the heat transfer coefficients at each location. However, the center quench residual stress distribution is approximately uniform and the stress magnitude is equal to the average of the stress magnitudes corresponding to the maximum and minimum heat transfer coefficients.
\end{abstract}

\section{Keywords}

Aluminum Alloy, Residual Stress, Asymmetric Distribution, Finite Element Method, Neutron Diffraction Method

\section{Introduction}

$\mathrm{Al}-\mathrm{Zn}-\mathrm{Mg}-\mathrm{Cu}$ aluminum alloys are widely used in the aircraft industry because of their high specific strength, specific stiffness and toughness, good machinability and excellent corrosion resistance [1] [2] [3]. Solid solution heat treatment is 
a necessary procedure to obtain the desired mechanical properties in the production process of $\mathrm{Al}-\mathrm{Zn}-\mathrm{Mg}-\mathrm{Cu}$ aluminum alloys. However, the quenching process generates huge residual stresses due to the large temperature gradient during the quenching process, which is detrimental to the performance properties [4]. In addition, for industrial plates with large plate thicknesses, the condition of asymmetric quenching is unavoidable and the distribution of residual stresses during quenching appears asymmetrical.

The quench residual stresses of aluminum alloys $\mathrm{Al}-\mathrm{Zn}-\mathrm{Mg}-\mathrm{Cu}$ have been studied both by experimental methods and numerical simulations [5]. Experimental methods mainly include neutron diffraction [6] [7] [8], X-ray [9], borehole drilling [10], layer stripping [11] etc. However, in previous studies, the quenching process was generally set as homogeneous and possible asymmetric quenching was ignored. Asymmetric quenching is versatile for industrial large-sized plates due to the complex industrial quenching procedure. The heat transfer conditions on the surface during the quenching process seem to be uneven. In the spray quenching process, the nozzle distribution and quench direction in the quenching system can lead to asymmetric quenching [12].

In this paper, two strategies of asymmetric quenching in an $\mathrm{Al}-\mathrm{Zn}-\mathrm{Mg}-\mathrm{Cu}$ aluminum alloy plate were simulated using finite element method. The distribution of surface and central residual stresses and the magnitude of the two asymmetric quenching strategies are discussed in detail. The relationship between residual stresses of asymmetric and uniform quenching is disclosed. In addition, a finite element model of residual stress quenching has been verified by neutron diffraction.

\section{Neutron Diffraction Measurement}

The material used in this study was a $27 \mathrm{~mm}$ thick $\mathrm{Al}-\mathrm{Zn}-\mathrm{Mg}-\mathrm{Cu}$ hardened aluminium alloy plate with the composition (wt\%) of $\mathrm{Zn}-7.99, \mathrm{Mg}-1.90, \mathrm{Cu}-2.20$, Zr-0.11, Fe-0.056, Si-0.0037, rest-Al. The plate had dimensions of $270 \mathrm{~mm}$ (RD, rolling direction $) \times 81 \mathrm{~mm}(\mathrm{TD}$, transverse direction $) \times 27 \mathrm{~mm}(\mathrm{ND}$, normal direction). Neutron diffraction measurements were performed on a neutron reactor (CARR) and the $\mathrm{Al}\{311\}$ planes were chosen as the diffraction plane. The measurement points were distributed in the normal direction from the centre of the body to the centre point of the surface and four points with an equal interval of $2 \mathrm{~mm}$ were measured.

\section{Simulation}

A sequential coupling of the temperature field and the stress field was applied in this simulation work, which was carried out by the ANSYS software. First, the temperature evolution and distribution were calculated through the boundary conditions and the heat transfer coefficient. Then, the results of the thermal simulation were used as initial conditions in the stress field simulation. Finally, the stress field result was obtained. An elastoplastic model was used in the study 
and bilinear kinematic quenching was used to describe the strain quenching.

The material used in the simulation work was an $\mathrm{Al}-\mathrm{Zn}-\mathrm{Mg}-\mathrm{Cu}$ aluminum alloy plate. The starting temperature of the quenching process was $475^{\circ} \mathrm{C}$ and it was assumed that there was no stress in the plate at the beginning. The water temperature was $20^{\circ} \mathrm{C}$. The material properties of the $\mathrm{Al}-\mathrm{Zn}-\mathrm{Mg}-\mathrm{Cu}$ aluminum alloy used in the FEM analysis were obtained by experimental tests and are described in ref. [13]. A $1 / 8$ model of the plate was used to reduce the simulation time by considering the symmetry characteristic of the plate. A 20-node 3-D thermal element (SOLID90 in ANSYS) was used for the simulation of heat transfer analysis and a 20-node 3-D structural element (SOLID186 in ANSYS) was used for the stress-displacement analysis. In this paper, through thickness means the path between the center points of the top and bottom surface; surface transverse direction means the path from the center point on the surface to the edge along the transverse direction; central transverse direction means the path from the center point of the body to the edge along the transverse direction.

\section{Results and Discussion}

Heat transfer coefficient distribution. A series of average heat transfer coefficients were used in this study to quantitatively simulate the asymmetric distribution of heat transfer coefficients on the surfaces of the hardened plate. The average heat transfer coefficients are $26,000\left(20^{\circ} \mathrm{C}\right), 20,500\left(40^{\circ} \mathrm{C}\right), 17,500\left(60^{\circ} \mathrm{C}\right)$ and $9500\left(80^{\circ} \mathrm{C}\right) \mathrm{W} \cdot \mathrm{m}^{-2} \cdot \mathrm{K}^{-1}$, which are taken from the literature [13]. Two asymmetric heat transfer coefficient distribution strategies were implemented in this study to reveal the residual quenching stress distributions under the asymmetric quenching process. One was the asymmetric heat transfer coefficient between the top and bottom surfaces with the uniform heat transfer coefficient on each surface. The three pairs of $20^{\circ} \mathrm{C} \& 40^{\circ} \mathrm{C}, 20^{\circ} \mathrm{C} \& 60^{\circ} \mathrm{C}, 20^{\circ} \mathrm{C} \& 80^{\circ} \mathrm{C}$ were simulated in this part. The other was the asymmetric heat transfer coefficient on the single surface while being centrosymmetric in the transverse direction. In this type of quenching process, the heat transfer coefficient decreased linearly from $26,000 \mathrm{~W} \cdot \mathrm{m}^{-2} \cdot \mathrm{K}^{-1}$ at the centre line to $5000 \mathrm{~W} \cdot \mathrm{m}^{-2} \cdot \mathrm{K}^{-1}$ at the edge (by linear interpolation).

Verification of the finite element model by the neutron diffraction method. To illustrate the efficiency and accuracy of the finite element model, the residual stress distribution across the thickness of the plate hardened at $20^{\circ} \mathrm{C}$ was measured by the neutron diffraction method, and the experimental results were compared with the simulation results. However, due to the limited testing time of the neutron diffraction method, only a few points in the center of the plate were measured, which was difficult to obtain by other methods. The comparison of the results is shown in Figure 1. It can be seen that the magnitude and stress distribution of the simulation results are very similar to those of the neutron diffraction results, both in the longitudinal and transverse components of the hardening residual stress. Thus, the simulated quenching residual stress in 


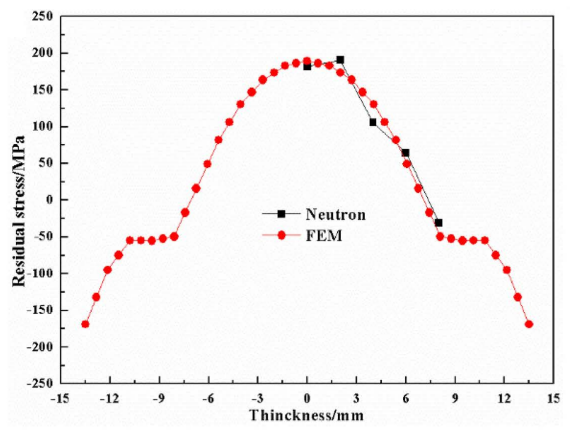

(a)

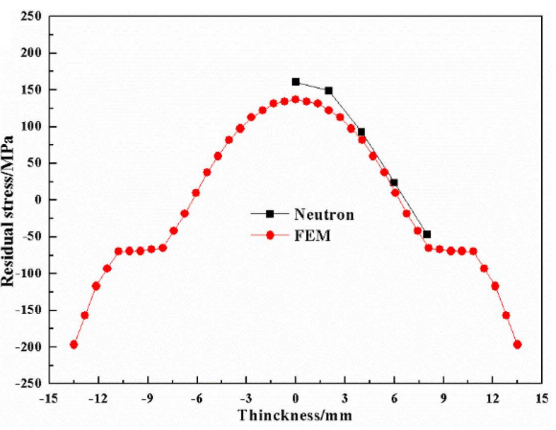

(b)

Figure 1. The comparison of the experimental and simulation result of through-thickness quenching residual stress distribution (a) longitudinal component; (b) transversal component.

this study was applicable for the prediction of the asymmetric distribution of the quenching residual stress.

Asymmetric heat transfer coefficient distribution within two surfaces. Since the longitudinal and transverse components of the residual stresses are almost identical in large plates [14] [15] [16], only the longitudinal and transverse components of the stresses were analyzed. $20^{\circ} \mathrm{C} \& 40^{\circ} \mathrm{C}, 20^{\circ} \mathrm{C} \& 60^{\circ} \mathrm{C}$ and $20^{\circ} \mathrm{C} \& 80^{\circ} \mathrm{C}$ through-thickness residual stress distributions under asymmetric quenching of the top and bottom surfaces are shown in Figure 2. It can be seen that the through-thickness residual stress distributions for asymmetric quenching lie between the two distributions corresponding to the heat transfer coefficients on the top and bottom surfaces respectively.

Table 1 and Table 2 summarize the surface and central residual stresses for the different asymmetric quenching conditions respectively. It can be concluded that the stress magnitude for both surface and central stresses is equal to the average of the stress levels corresponding to the two surface heat transfer coefficients.

Asymmetric heat transfer coefficient distribution within a single surface. Figure 3 shows the distribution of quench residual stresses for asymmetric heat transfer coefficients within a single surface. Compressive stresses appear at the surface, while tensile stresses appear at the center. The surface quenching residual stresses are asymmetrically distributed in the transverse direction and uniformly distributed in the rolling direction except for the edge regions. However, the central quench residual stresses are relatively uniformly distributed.

Figure 4 shows the distribution of asymmetric heat transfer coefficients along the transverse direction for surface quenched residual stresses. It can be seen that the surface quenched residual stresses show an approximate distribution of asymmetric heat transfer coefficients in the transverse direction. The stresses decrease from 193.9 $\mathrm{MPa}$ at the centre to $13.3 \mathrm{MPa}$ at the edges where there is a linear decrease from the $20^{\circ} \mathrm{C}$ water quenched position to the $80^{\circ} \mathrm{C}$ water quenched position. Furthermore, the magnitude of the stresses at each location during asymmetric quenching is approximately equal to that of the stresses 


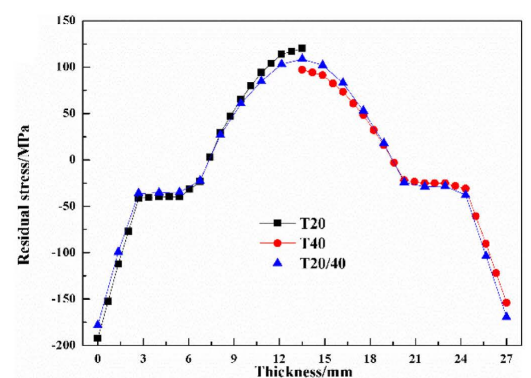

(a)

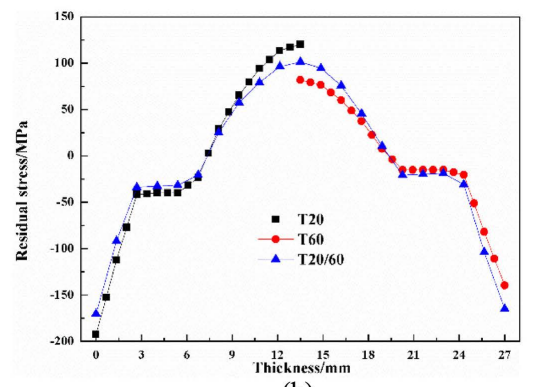

(b)

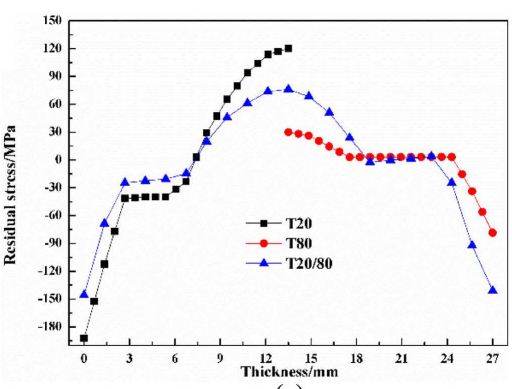

(c)

Figure 2. Through thickness quenching residual stress distributions. (a) $20^{\circ} \mathrm{C} \& 40^{\circ} \mathrm{C}$; (b) $20^{\circ} \mathrm{C} \mathrm{\&} 60^{\circ} \mathrm{C}$; (c) $20^{\circ} \mathrm{C} \mathrm{\&} 80^{\circ} \mathrm{C}$.

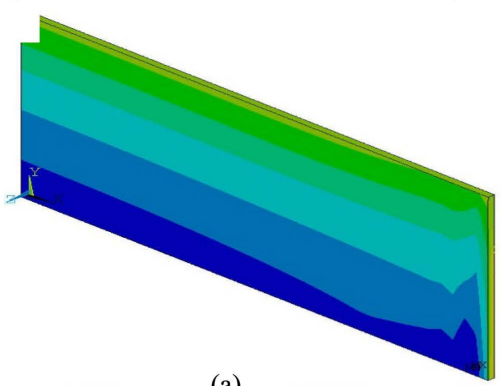

(a)

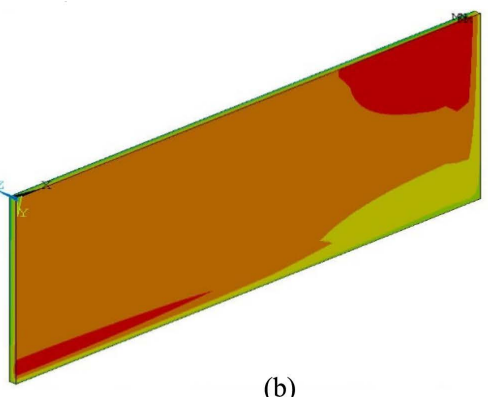

(b)

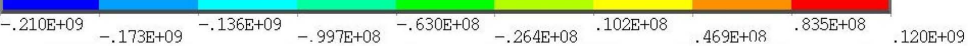

Figure 3. Asymmetric quenching residual stress distribution (a) surface; (b) center.

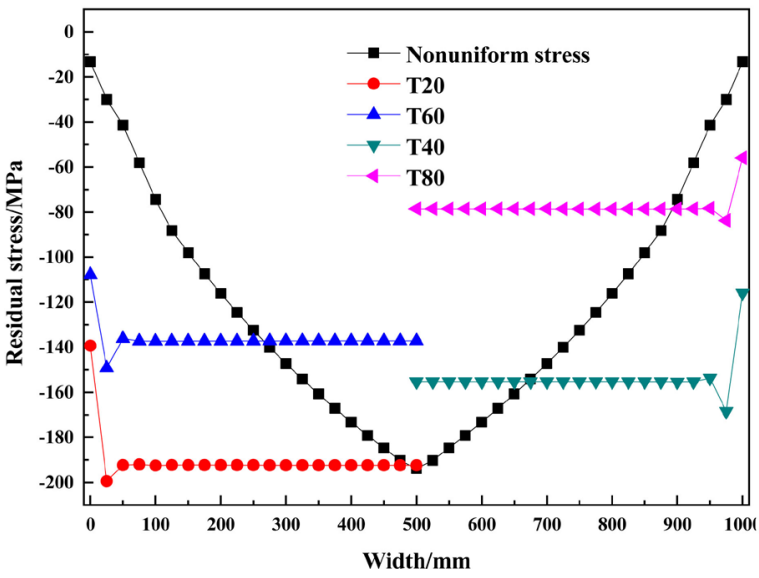

Figure 4. Surface quenching residual stress distribution along the transverse direction.

Table 1. Surface residual stress of different asymmetric quenching condition (Unit: MPa).

\begin{tabular}{cccc}
\hline & Initial stress & Average stress & Stress (asymmetric) \\
\hline $20^{\circ} \mathrm{C} \& 40^{\circ} \mathrm{C}$ & -192.4 & -173.2 & $-178.3 /-169.3$ \\
\hline $20^{\circ} \mathrm{C} \& 60^{\circ} \mathrm{C}$ & -153.0 & & $-170.5 /-165.0$ \\
\hline $20^{\circ} \mathrm{C} \& 80^{\circ} \mathrm{C}$ & -192.4 & -166.0 & $-145.7 /-141.0$ \\
\hline
\end{tabular}


during uniform quenching. The quenching process can be assumed to be an approximately one-dimensional heat transfer process through the direction normal to the surface region. Due to the rapid cooling of the surface region, the temperature gradient difference between adjacent regions cannot be completely neutralized. Therefore, the corresponding residual stress magnitudes can be stabilized after cooling down. It can therefore be concluded that the surface hardening residual stresses for asymmetric quenching maintain the initial stress magnitude of the heat transfer coefficient at each location along the transverse direction.

Figure 5 shows the distribution of residual stresses in the central quench along the transverse asymmetric heat transfer coefficient. It can be seen that the effect of asymmetric quenching on the central quench residual stresses is different from the effect on the surface stresses. As shown in Figure 5, the central quench residual stresses are almost identical at all locations for both $20^{\circ} \mathrm{C}$ water quenching and $80^{\circ} \mathrm{C}$ water quenching (within the red line, the stress deviation is less than $10 \mathrm{MPa}$ ). In addition, the stress magnitude for the $20^{\circ} \mathrm{C}$ water quench is $120 \mathrm{MPa}$, while the stress magnitude at the quench edge with a heat transfer coefficient of $5000 \mathrm{~W} \cdot \mathrm{m}^{-2} \cdot \mathrm{K}^{-1}$ is $10 \mathrm{MPa}$. Based on the simulation results in Figure 5 , the stress magnitude is approximately $65 \mathrm{MPa}$, which is exactly the average of the two extremes. It can be concluded that the central quench residual stress distribution is approximately uniform and the stress level is equal to the average of the stress levels corresponding to the maximum and minimum heat transfer coefficients.

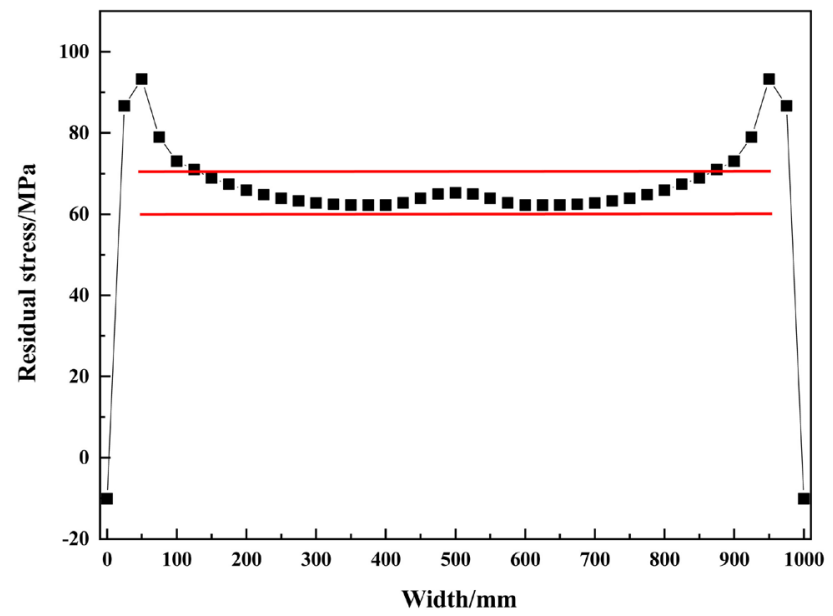

Figure 5. Center quenching residual stress distribution along the transverse direction.

Table 2. Center residual stress of different asymmetric quenching condition (Unit: MPa).

\begin{tabular}{cccc}
\hline & Initial stress & Average stress & Stress (asymmetric) \\
\hline $20^{\circ} \mathrm{C} \mathrm{\&} 40^{\circ} \mathrm{C}$ & 120.3 & 108.8 & 108.9 \\
\hline $20{ }^{\circ} \mathrm{C} \& 60^{\circ} \mathrm{C}$ & 97.3 & 101.2 & 101.4 \\
\hline $20{ }^{\circ} \mathrm{C} \& 80^{\circ} \mathrm{C}$ & 120.3 & & 76.2 \\
\hline
\end{tabular}




\section{Conclusions}

When the top and bottom surfaces of the plate are in the asymmetric quenched state, the through-thickness asymmetric quench residual stress distribution lies between the two distributions corresponding to the heat transfer coefficients on the top and bottom surfaces respectively. The surface and center stress magnitudes are equal to the average of the stress magnitudes corresponding to the heat transfer coefficients of the two surfaces.

When the surface is quenched asymmetrically, the surface stress distribution is the same as the heat transfer coefficient distribution and the stress magnitude is equal to the stress magnitude corresponding to the average of the heat transfer coefficients at each location. However, the central quenching residual stress distribution is approximately uniform and the stress magnitude is equal to the average of the stress magnitudes corresponding to the maximum and minimum heat transfer coefficients.

\section{Acknowledgements}

This study was financially supported by National Key R \& D Program of China (No. 2020YFF0218203, 2020YFF0218202) and Youth Fund Project of GRINM (G12620203129012).

\section{Conflicts of Interest}

The authors declare no conflicts of interest regarding the publication of this paper.

\section{References}

[1] Dursun, T. and Soutis, C. (2004) Recent Developments in Advanced Aircraft Aluminium Alloys. Materials \& Design, 56, 862-871. https://doi.org/10.1016/j.matdes.2013.12.002

[2] Williams, J.C. and Starke, E.A. (2003) Progress in Structural Materials for Aerospace Systems. Acta Materialia, 51, 5775-5799. https://doi.org/10.1016/j.actamat.2003.08.023

[3] Toros, S., Ozturk, F. and Kacar, I. (2008) Review of Warm Forming of Aluminum-Magnesium Alloys. Journal of Materials Processing Technology, 207, 1-12. https://doi.org/10.1016/j.jmatprotec.2008.03.057

[4] Prantil, V.C., Callabresi, M.L., Lathrop, J.F., Ramaswamy, G.S. and Lusk, M.T. (2003) Simulating Distortion and Residual Stresses in Carburized Thin Strips. J. Eng. Mater. Technol., 125, 116-124. https://doi.org/10.1115/1.1543973

[5] Tanner, D.A. and Robinson, J.S. (2003) Modelling Stress Reduction Techniques of Cold Compression and Stretching in Wrought Aluminum Alloy Products. Finite Elem Anal Design, 39, 369-386. https://doi.org/10.1016/S0168-874X(02)00079-3

[6] Pratihar, S., Stelmukh, V., Hutehings, M.T., Stuhr, U. and Edwards, L. (2006) Measurement of the Residual Stress Field in MIG-Welded Al-2024 and Al-7150 Aluminium Alloy Compact Tension Specimens. Mat Sci Eng A, 437, 46-53. https://doi.org/10.1016/j.msea.2006.04.061

[7] Woo, W., Feng, Z., Wang, X.L. and Hubbard, C.R. (2009) Neutron Diffraction 
Measurements of Time-Dependent Residual Stresses Generated by Severe Thermomechanical Deformation. Scripta Mater, 61, 624-627.

https://doi.org/10.1016/j.scriptamat.2009.05.040

[8] Prime, M.B., Gnäupel-Herold, T., Baumann, J.A., Lederich, R.J., Bowden, D.M. and Sebring, R.J. (2006) Residual Stress Measurements in a Thick, Dissimilar Aluminum Alloy Friction Stir Weld. Acta Mater, 54, 4013-4021.

https://doi.org/10.1016/j.actamat.2006.04.034

[9] Robinson, J.S., Tanner, D.A., Truman, C.E., Paradowska, A.M. and Wimpory, R.C. (2012) The Influence of Quench Sensitivity on Residual Stresses in the Aluminum Alloys 7010 and 7075. Mater Charact, 65, 73-85. https://doi.org/10.1016/j.matchar.2012.01.005

[10] Xu, W.F., Liu, J.H. and Zhu, H.Q. (2011) Analysis of Residual Stresses in Thick Aluminum Friction Stir Welded Butt Joints. Mater Design, 32, 2000-2005.

https://doi.org/10.1016/j.matdes.2010.11.062

[11] Virkar, A.V. (1990) Determination of Residual Stress Profile Using a Strain Gage Technique. J Am Ceram Soc, 73, 2100-2102. https://doi.org/10.1111/j.1151-2916.1990.tb05276.x

[12] Guo, R.C., Wu, J.J., Fan, H. and Zhang, X.P. (2016) The Effects of Spray Characteristic on Heat Transfer during Spray Quenching of Aluminum Alloy 2024. Exp Therm Fluid Sci, 76, 211-220. https://doi.org/10.1016/j.expthermflusci.2016.03.025

[13] Li, Y.N., Zhang, Y.A., Liu, H.L., Lv, X.Y., Li, X.W., Li, Z.H., Yan, H.W., Wen, K. and Xiong, B.Q. (2020) Residual Stress Distribution of Non-Uniform Quenching in Al-Zn-Mg-Cu Aluminum Alloy Thick Plate. Mater Sci Forum, 1003, 11-19. https://doi.org/10.4028/www.scientific.net/MSF.1003.11

[14] Zhang, J., Zheng, L., Guo, X.B., Ji, V. and Klosek, V. (2014) Residual Stresses Comparison Determined by Short-Wavelength X-Ray Diffraction and Neutron Diffraction for 7075 Aluminum Alloy. J Nondestruct Eval, 33, 82-92. https://doi.org/10.1007/s10921-013-0205-9

[15] Dong, Y.B., Shao, W.Z. and Lu, L.X. (2015) Numerical Simulation of Residual Stress in an Al-Cu Alloy Block during Quenching and Aging. J Mater Eng Perform, 24, 4928-4940. https://doi.org/10.1007/s11665-015-1758-9

[16] Zhang, L., Feng, X., Li, Z.G. and Liu, C.Y. (2013) FEM Simulation and Experimental Study on the Quenching Residual Stress of Aluminum Alloy 2024. P I Mech Eng B-J Eng, 227, 954-964. https://doi.org/10.1177/0954405412465232 